\title{
Fingimento, mimese e verdade na literatura: Lisboa, a cidade de Ulisses
}

Make-believe, mimesis and truth in literature: Lisbon, the city of Ulisses

\author{
Lúcia Helena Marques Ribeiro
}

\section{RESUMO}

A Arte não significa imitação do mundo exterior, mas fornece possíveis interpretações do real. $\mathrm{O}$ mito canaliza as ações para o significado humano de uma experiência existencial imaginária, objeto de uma interpretação possível. Este texto tem por objetivo propor uma reflexão sobre o papel da literatura como arte mediadora entre o mito, o homem e a sua história. Para tanto, revê essas questões na literatura portuguesa através da obra $A$ cidade de Ulisses $^{1}$ da autora Teolinda Gersão.

Palavras-chave: Mimese; Fingimento; Verdade; Mito; Memória; História.

\begin{abstract}
Art is not an imitation of the exterior world, but it provides possible interpretations of the true. The myth channels the actions to the human meaning of an imaginary existential experience, object of a possible interpretation. This paper aims at proposing a reflection on the role of the Literature as a mediator art between the myth, the man and his history. Therefore, it reviews these issues within the Portuguese Literature through the work City of Ulisses written by Teolinda Gersão.
\end{abstract}

Keywords: Mimesis; Make-believe; Truth; Myth; Memory; History.

Professora Adjunta do Departamento de Teoria Literária e Literatura da Universidade de Brasília (UnB). Doutora em Teoria Literária pela Pontifícia Universidade Católica do Rio Grande do Sul. Atualmente cursa Pós-Doutorado em "Literatura para crianças e adolescentes" pela Universidade Federal do Rio Grande do Sul. Trabalha com Literaturas em Língua Portuguesa, com pesquisas em temas como emigração, memória, identidade cultural, pós-colonialismo e pós-modernidade. 
E tu, nobre Lisboa, que no mundo

Facilmente das outras és princesa, Que edificada foste do facundo Por cujo engano foi Dardânia acesa; Tu, a quem obedece o mar profundo, Obedeceste à força portuguesa, Ajudada também da força armada Que das boreais partes foi mandada. ${ }^{2}$

Sempre que tenho que dar uma aula ou falar sobre mimese ou sobre a questão da representação na literatura, o que me vem à mente são os quadros de René Magritte - Ceci n'est pas une pomme; Ceci n'est pas une pipe. Não conheço exemplos melhores para explicar a representação na arte. O cachimbo está lá, assim como a maçã. Mas não é um cachimbo e não é uma maçã. No entanto, o efeito causado pelo filtro chamado estética, naquele momento, nos leva a ver e a crer um cachimbo e uma maçã.

Segundo Lígia Militiz da Costa $^{3}$, a palavra mimese, no início da civilização grega, não tinha um significado único, porém mimésthai referiase ao ato de imitar, representar ações. A Poética ${ }^{4}$ de Aristóteles, em que pese o fato de ter sido escrita há mais de dois mil anos e ser provavelmente apenas parte de uma obra maior, é, indiscutivelmente, o ponto de partida de um pensamento teórico que discute e coloca a literatura como produto da criatividade humana - a poesia que trabalha as ações humanas provindas do mito - mimese, reproduzindo a verossimilhança e a necessidade. Se Platão, na sua obra República ${ }^{5}$, foi o primeiro a utilizar o termo, foi Aristóteles quem privilegiou o prazer como elemento fundamental para a arte enquanto ação humana.

Platão considerava a poesia nociva por afastarse da verdade e por estimular as paixões. Via a mimese como uma produção de cópias e não o projeto original, o que provocava um afastamento do conhecimento verdadeiro. Aristóteles defendia a poesia, dizendo ser verdadeira e útil porque acaba por trazer em si uma função social, dado que produz conhecimento (com prazer) e evidencia a necessidade da vida como algo inteligível, faz pensar a própria vida, e com isso, acaba por mostrar a verdade:

O mito é o nada que é tudo.

O mesmo sol que abre os céus

É um mito brilhante e mudo

o corpo morto de Deus,

Vivo e desnudo. ${ }^{6}$

A literatura portuguesa desde o seu início é feita dos seus mitos históricos ou lendários. Nação e literatura nasceram juntas em Portugal. Desde então, a construção dessa nação é contada e recontada como forma de confirmação dos mitos que formaram a identidade do povo.

A Cidade de Ulisses publicada em 2011, da autora Teolinda Gersão, é uma dessas obras que escava por meio da narrativa um dos principais mitos portugueses:

1 GERSÃO, Teolinda. A cidade de Ulisses. Rio de Janeiro: Oficina Raquel, 2017.

2 CAMÕES, Luis Vaz de. Os Lusíadas. Rio de Janeiro: Biblioteca do Exército, 1980, Canto III, 57, p. 219. 3 COSTA, Lígia Militz da. Mimese e verossimilhança: na Poética de Aristóteles e na teoria da literatura contemporânea. Porto Alegre: 1986. 303p. Tese de doutorado em Letras (Teoria da Literatura), Pontifícia Universidade Católica do Rio Grande do Sul.

4 ARISTÓTELES. Poética. São Paulo: Ars Poética, 1992. 5 JAEGER, Werner. Paideia - A formação do homem grego. São Paulo: [s.d.]

6 PESSOA, Fernando. Mensagem. São Paulo: Companhia das Letras, 1998, p. 23. 
Segundo a lenda, Ulisses dera a Lisboa o seu nome, Uliseum, transformado depois em Olisipo através de uma etimologia improvável [...] O que dava à cidade um estatuto singular, uma cidade real criada pela personagem de um livro, contaminada, portanto, pela literatura, pelo mundo da ficção e das histórias contadas. Joyce partira do nada para escrever o Ulisses, Dublin estava completamente fora da rota imaginária da personagem de Homero. Lisboa, pelo contrário, estava historicamente ligada à Grécia, às rotas marítimas e comerciais dos gregos. ( $p .43)$

O obra caminha por uma história de amor entre dois artistas plásticos que planejam juntos uma exposição sobre Lisboa, como a cidade fundada por Ulisses, e os passos que revisam as camadas históricas que a cidade esconde embaixo das muitas calçadas e revestimentos que foram se acumulando ao longo dos séculos. O casal se separa, a exposição fica no projeto e, muitos anos depois, Paulo Vaz, o par que havia ficado em Lisboa, recebe um convite para organizar uma exposição cujo tema seria justamente o olhar sobre a cidade. Ao reativar o projeto, ele revive o passado com Cecília, e acaba por reencontrar também a amante que partira para Londres à época do rompimento, retornando anos depois, mas que morre logo após esse reencontro. A exposição acaba acontecendo com a ajuda do marido dela e em sua homenagem.

Enquanto a história de amor é relembrada, e as imagens de Lisboa feitas por Cecília são organizadas para a exposição, também são reconstituídos os lugares de uma cidade que já teve outros formatos e outras superfícies, deixando à mostra as provas das civilizações que por ali aportaram como velhas cicatrizes:
Uma cidade a conquistar, em que se ia penetrando pouco a pouco e descobrindo, abaixo da superfície, outras camadas do tempo. (Saber por exemplo que o Tejo chegava à Rua dos Bacalhoeiros e vinha bater contra as muralhas, que a cidade se foi estendendo ao longo do cais e das praias, que na Praça da Figueira se juntavam duas ribeiras, uma descendo do vale de Arroios, outra do vale de Santo Antão, que os talvegues ainda se apresentem em ruas de nível mais deprimido, como o Regueirão dos Anjos, que na Avenida da Liberdade já foram as hortas de São José e o Valverde, que se ia veranear para as quintas do Arco Cego ou de Benfica, que no lugar do teatro D. Maria, no Rossio, já foi o Palácio dos Estaus, que a Cerca Moura na verdade é anterior, sueva, visigótica, que o Hospital de Todos os Santos ficava na Praça da Figueira, que o Arco Escuro de Alfama já foi a Porta do Mar). (p. 70)

Mas eram as "pegadas" de Ulisses que os protagonistas buscavam como o norte da exposição. Ulisses era o mito e a verdade absoluta. "A civilização helênica foi culturalmente o ponto mais alto da Europa”, por isso voltavam a ela "à procura de raízes" (p. 78).

Mas no nosso imaginário Ulisses, o grego, representava o legado helênico. Saía da sua época arcaica, da sua ilha de pastores $e$ marinheiros, navegava pelo tempo levando três coisas fundamentais que a Grécia deixara ao mundo: além da Odisseia, a Racionalidade e a Democracia. (p. 79)

Ao longo da narrativa, a montagem da exposição era a reconstituição da Lisboa mítica, e por se tratar de mitos, perdidos no tempo, sem provas então, da sua passagem, como Ulisses, ou Caio Júlio Cesar que ali viveu e foi feliz, mas foi esquecido. Como foram esquecidos os fenícios, 
prováveis fundadores vindos para comercializar com a população ibérica nativa, e também os cartagineses que haviam derrotado os romanos nas guerras púnicas e ali chegaram antes deles:

Era fácil ligar esses vestígios a Ulisses, $e$ efabular sobre uma Lisboa grega, anterior à romana, que começou em 138 a.C., de que existem numerosas ruínas e algumas se podem visitar até hoje. (p. 45)

A história de amor do casal se confunde com o amor à cidade. "Amar uma pessoa é falar-lhe quando ela não está presente, disse alguém. Porque ela se instalou dentro de nós. Tornou-se um objeto interior, uma parte de nós que só a nós diz respeito" (p. 217). Paulo apaixonou-se por Cecília quando era seu professor. Devagar, foram ficando muito próximos. Ela vinda de Lourenço Marques. Ele acostumado aos hábitos de Berlim. Morar junto foi o destino escolhido. Então começaram a explorar a cidade. A cidade de Ulisses. Refizeram caminhos. Descobriram Troia, uma península pequena achada após uma travessia de ferry-boat apanhado em Setúbal. Uma praia deserta na qual desenharam, com um graveto na areia molhada, a viagem de Ulisses: pelo Mediterrâneo, passando por Gibraltar, ou Colunas de Hércules, como diziam os antigos, contornando a Península Ibérica e o que depois seria o Algarve, subiria a costa até Alcácer do Sal e Setúbal subindo o rio, desde a foz até o anfiteatro da cidade a qual o herói colocaria o seu próprio nome. Amavam um a outro e os dois amavam os mitos que fizeram de Lisboa a "cidade vertical":

Deparávamos com um conjunto de fragmentos, restos de cidades construídas uma sobre as outras, de épocas e civilizações que chegavam a um impasse e desapareciam.
Deixando marcas. A cidade crescera assim verticalmente desde o subsolo, encontravamse escavações e museus elementos da cultura nativa, estátuas de deuses como Endovélico, elementos fenícios, romanos, visigóticos, $e$ numerosos vestígios da cidade árabe. (p. 72)

Um dia Cecília descobriu-se grávida. Paulo não queria filhos. Viu-se traído pela mulher que amava. Empurrou-a de uma escada. Cecília foi-se embora. Perdera o bebê e a sua vida em Lisboa.

Dez anos depois, o convite que Paulo recebera para a exposição fez com que pensasse no antigo projeto que idealizara com Cecília. Precisaria por o nome dela como coautora. Acaba encontrando-a casualmente em uma exposição. Cumprimentam-se rapidamente. Depois tornaram a se encontrar em um grande mercado. Conseguiram tomar um café juntos. Trocaram números de telefones. Paulo conheceu as filhas dela. Estava casada com outro homem. Ele com outra mulher. Um acidente de carro leva Cecília da vida de Paulo novamente. Dessa vez para sempre, o deixando com a certeza de uma conversa também para sempre inacabada:

Muitas vezes, anos atrás, eu pensava em ir buscar-te, subir os degraus, entrar no elevador, arrombar a porta da tua casa, arrastar-te à força, levar-te comigo, mesmo que não quisesses. Mas agora vinhas, por vontade própria, sentar-te aí, nessa cadeira. Como anos atrás eu olhava no ateliê a tua cadeira vazia. Interrogava-me como teria sido, se tivesse vivido a vida toda contigo. Se era a tua ausência que te tornava única, porque através da imaginação eu te via maior do que o real. Imaginava o que dirias: - $E$ muito fácil ser o maior dos amantes, se houver o mar ou a morte de permeio. Ulisses 
ama Penélope acima de tudo no mundo, se entre eles estiver o mar e ele puder amar todas as mulheres, dirias. Com a lucidez que sempre te conheci. (p. 217)

A mitologia é uma forma de arte e a Literatura ao longo dos tempos tem cumprido a função de criar mitos como forma de recriação da história ou de perspectivas da história e de seus vários heróis, ou anti-heróis. A Literatura cumpre esse papel de transcendência reconstruindo os mitos, ou não deixando que eles morram com os seus rituais e significados. Assim temos a origem de muitos mitos fundacionais de muitas nações perdidos nas brumas dos tempos. No ciclo Bretão, por exemplo, temos a trilogia do Rei Artur para contar o mito de fundação de um reino, cujo rei possuía uma espada mágica, Excalibur, que com ela fundou Camelot, e reinou com justiça e sabedoria, juntamente com seus doze cavaleiros, pelo menos enquanto isso foi possível... Esse mito sobrevive por séculos e serviu mesmo como modelo para outros tantos mitos e cortes europeias. Mas não foi a Inglaterra a nação mais antiga da Europa e nem a que teve na sua fundação mais heróis, cavaleiros nobres ou plebeus, ou conquistas míticas.

Portugal começou a nascer com o mito de Ulisses que fundou "Olisipo Bona”, a boa cidade de Ulisses, ao qual sucederia o mito de Viriato, o pastor montanhês lusitano que lutou sob as ordens de Hermínio e resistiu por oito anos aos romanos. O nascimento de Portugal como nação se deve ao surgimento de outro mito, ao da Ordem dos Cavaleiros Templários, anunciada pelo Papa Eugenio III em carta enviada a São

7 PAGE, Martin. A primeira aldeia global - como Portugal mudou o mundo. Alfragide: Casa das Letras, 2012, p.33. 8 PESSOA, Fernando. Mensagem. São Paulo. Companhia das Letras, 1998, p.28.
Bernardo de Clarvaux na Borgonha. A Ordem dos Cavaleiros do Templo se constituiu para apoiar Afonso Henriques que havia vencido o exército da mãe, D. Teresa e começado a reconquista cristã da Península Ibérica, vencendo a Batalha de Ourique. Afonso Henriques foi reconhecido pelo papa como o primeiro rei de Portugal, e Portugal foi a primeira nação independente da Europa.

o papel dos portugueses não foi o de conquistadores, muito menos o de conquistados, mas antes, o de um povo pivô, uma espécie de conduta através da qual as ideias, o conhecimento e as tecnologias se transmitiram à Europa e ao mundo". ${ }^{7}$

Portugal promoveu o maior feito da civilização moderna em pleno século XV. Desenvolveu a tecnologia das caravelas que foi o que propiciou a quebra do isolamento existente entre a Europa e o resto do mundo. Essas novas naus com velas triangulares à popa e à ré, conseguiam propulsionar o navio para frente, permitindo que ele velejasse à bolina, contra o vento, atingindo uma velocidade de dez nós por hora, foram decisivas para a conquista marítima. Uma tecnologia desenvolvida graças à inteligência visionária de um rei, D. João II, que fundou um Conselho de Sábios constituído por eclesiásticos, rabinos, matemáticos e cosmógrafos eminentes. Ou duzentos anos antes, graças a um rei culto e sua mulher, que resolveram plantar pinhais que serviriam futuramente de madeira para essas embarcações. O plantador de naus, o mito que um dia Fernando Pessoa cantaria:

Na noite escreve um seu Cantar de Amigo O plantador de naus a haver,

E ouve um silêncio múrmuro consigo:

É o rumor dos pinhais que, como um trigo

De Império, ondulam sem se poder ver. ${ }^{8}$ 
Durante a leitura de A cidade de Ulisses, não raro para-se para pensar em outras obras, de tantos escritores portugueses que, como Teolinda Gersão, saem em busca das escavações da própria identidade, revirando na memória da história e do pertencimento, muitas vezes sem conseguir separar mito e realidade:
Este que aqui aportou,
Foi por não ter existindo.
Sem existir nos bastou.
Por não ter vindo foi vindo
E nos criou. ${ }^{9}$

Em a História do cerco de Lisboa ${ }^{10}$ de José Saramago, Raimundo Silva faz consultas minuciosas em notas mentais, enquanto segue os próprios passos caminhando por Lisboa, calculando os locais onde teria sido erguida a cerca pelos mouros para defender a cidade conquistada e mantida por mais de trezentos anos. A história do cerco de Lisboa que chegou até nós provém de um relato testemunhal de um padre normando, que acompanhou os cavaleiros da Ordem dos Templários, os quais, junto com os cruzados normandos e ingleses, juntaram-se a Afonso Henriques, quando ele mandou ao governador muçulmano o recado de que teria três dias para se render lá no ano da graça de 1147. Lisboa tinha ficado 370 anos sob o domínio dos muçulmanos, período, aliás, de convivência bastante pacífica entre cristãos, judeus e árabes:

Raimundo Silva não tem pressa. Consulta gravemente o itinerário, por sua satisfação vai tomando minuciosas notas mentais, por assim dizer complementares, que atestam sua própria contemporaneidade, lá na calçada do Correio Velho uma soturna agência funerária [...] mesmo ao Lado das Portas do Mar a Cervejaria Arco da Conceição, no dito, a alta pedra de armas dos Mascarenhas no cunhal de um prédio do Arco de Jesus, onde teria sido uma porta da cerca moura... (p. 64)

É a mesma caminhada por Lisboa feita por Cecília e Paulo, que tenta refazer o diálogo amoroso e crítico com a cidade e com a sua história:

O revisor, cansado, sobe à Rua dos Cegos, entra no Pátio de D. Fradique, o tempo abrese em dois ramos para não tocar nessa aldeia rupestre, está assim, a bem dizer, desde os godos, ou os romanos, ou os fenícios, depois é que vieram os mouros, os portugueses de raiz, os filhos e os netos deles, estes que somos, o poder e a glória, as decadências, primeira, segunda e terceira, cada uma delas dividida em gêneros e subgêneros. À noite, neste espaço entre as casas baixas, juntam-se os três fantasmas, o do que foi, o do que esteve para ser, o do que poderia ter sido, não falam, olham-se como se olham cegos, e calam. ${ }^{11}$

Raimundo Silva vai além do seu papel de revisor da obra sobre a história do cerco de Lisboa a qual o confiaram para tal tarefa, e assim o faria se não sofresse e caísse na tentação de se aproveitar de uma frase na qual coloca um "não" que modificaria toda a história da cidade e de Portugal:

Mas esta batalha, desgraçadamente, ia ganhála Mr. Hyde, percebe-se pela maneira como Raimundo Silva está a sorrir neste momento, com uma expressão que não esperaríamos dele, de pura malignidade, desapareceram-lhe do rosto todos os traços do Dr. Jekill, é evidente que acabou de tomar uma decisão, $e$ que má ela foi, com a mão firme segura a esferográfica e acrescenta uma palavra à

9 Idem, p.23.

10 SARAMAGO, José. História do cerco de Lisboa. São Paulo: Companhia das Letras, 2011.

11 Idem, p.66. 
página, uma palavra que o historiador não escreveu, que em nome da verdade histórica não poderia ter escrito nunca, a palavra Não, agora o que o livro passou a dizer é que os cruzados Não auxiliarão os portugueses a conquistar Lisboa, assim está escrito $e$ portanto passou a ser verdade, ainda que diferente, o que chamamos falso prevaleceu sobre o que chamamos verdadeiro, tomou o seu lugar, alguém teria de vir contar a história nova, e como. (p. 42)

A história transcorre através de sobreposições temporais. Na mesma hora em que é narrado o amanhecer de Lisboa ainda muçulmana, a despertar com a voz do almuaden a ecoar pela cidade a chamar os fiéis para a reza, o horizonte com a visão parcial da cidade, tapado por uma neblina é visto do alpendre da casa do revisor que dá continuidade à narrativa. Assim como as cenas na "Leitaria A Graciosa", que se sucedem misturando os tempos, o do cerco e o do revisor:

Evidentemente, a Leitaria A Graciosa, onde o
revisor agora vai entrando, não se
encontrava aqui no ano de mil cento e
quarenta e sete em que estamos, sob este céu
de junho, magnifico e cálido apesar da brisa
fresca que vem do lado do mar, pela boca do
mar. Uma leitaria é, desde sempre, um bom
lugar para saber as novidades, em geral as
pessoas não trazem muita pressa [...] a cidade
está um coro de lamentações com toda essa
gente que vem entrando fugida, enxotada
pelas tropas de Ibn Arrinque, o Galego, que
Alá o fulmine e condene ao inferno profundo,
e vêm em lastimoso estado os infelizes,
escorrendo sangue de feridas, chorando e

12 PESSOA, Fernando. Mensagem. São Paulo: Companhia das Letras, 1998, p. 23.

13 MELO, João de. O homem suspenso. Lisboa:

Publicações D. Quixote, 1996, p. 30. gritando, não poucos trazendo cotos em lugar de mãos, ou cruelmente desorelhados, ou sem nariz, é o aviso que manda adiante $o$ português, E parece, diz o dono da leitaria, que vêm cruzados por mar, malditos sejam eles... (p. 54)

Depois do erro histórico conscientemente provocado pelo revisor no texto, cabe a ele encontrar algum álibi que possa tornar possível tamanha mudança. Passa a considerar várias hipóteses, todas impossíveis de comprovar tamanho desvario cometido, imaginando o discurso irônico dos cruzados para o rei Afonso:

Senhor rei, nós aqui não ficamos, apesar deste bom sol que cá têm, destas veigas fertilíssimas, destes lavados ares, deste rio tão formoso onde saltam as sardinhas, quedevos vossa mercê e que lhe faça bom proveito, adeus. (p. 112)

Raimundo Silva acaba por escrever seu próprio romance com os personagens da história do cerco, tão vivos estavam para ele. Não poderia ser mero revisor de uma história a qual queria intervir, ou intervia diariamente nas suas caminhadas, ao reconhecer em Lisboa um palimpsesto, muitas camadas de histórias mal apagadas por outras que vieram depois:

Assim a lenda se escorre A entrar na realidade, E a fecundá-la decorre Em baixo, a vida, metade De nada, morre. ${ }^{12}$

Um homem vaga por Lisboa. Abandonou a sua casa, a mulher que amava, carregava apenas a sua tese no banco do carro, que será atirada às águas do Tejo. "Estou eu próprio escrito na minha tese, morto nela. Este é o livro ardido da minha vida, a escrita das minhas cinzas”13. Em 
O homem suspenso (1996), o escritor açoriano João de Melo desenvolve uma narrativa que, a partir de uma personagem que peregrina por Lisboa, questiona a europeização de Portugal, que finalmente passava a integrar a

Comunidade Europeia e o sentimento do português que se sentia ameaçado por essa nova identidade:

Perdi o mapa e o território daquilo em que aprendi a acreditar: o amor, o casamento, $o$ trabalho, o meu país, o destino de um mundo a que bem se pode dar o nome de pátria, digo, de exílio no meu sentimento de família. (p. 49)

Num impulso, atira a sua tese ao rio. "Fico a ver a minha ave de papel debater-se, ser apanhada na corrente do grande rio que passa ignorado por Lisboa” (p. 30). Ele também não reconhece a sua nova identidade de europeu e também não se reconhece, agora, fora daquele casamento, e fora da vida de professor acadêmico que sempre havia exercido. Dirige o seu carro pelas avenidas da cidade, sem rumo certo, recapitulando os passos da sua vida em comum com a mulher e com a amante açoriana. "Vejo Lisboa deslizar à minha ilharga, as trêmulas luzes ondulantes de uma cidade a um tempo nítida e virtual” (p. 32). Precisa de um lugar para ficar, mas precisa também vencer uma crise de pânico, ou um caixa eletrônico, agora integrado ao bloco financeiro continental; precisa peregrinar pela cidade sem saber ainda o que busca. Se sente em suspenso:

Sou um homem da periferia, um cidadão da margem, do mar. Desconheço outro qualquer sentimento europeu. Não imagino sequer a Europa que entrou nas minhas fronteiras se é esta que sempre me foi vizinha e ressentida, se a outra que vem agora na nova cúpula de um artifício que se estendeu sobre mim como uma abóboda, uma sombra imensa, invadindo-me, ocupando-me no escuro da noite para o dia, e subtraindo-me aos mitos portugueses da terra e do mar. Os meus mitos portugueses são: a árvore da minha floresta, a agricultura do vinho e dos pomares, a cidadania da paisagem e do dia, e este infinito mar que nos habita imanente, sábio $e$ necessário ao olhar. (p. 26)

Perdera o amor da mulher por negligência confessa - "Claro que o sabia! Sempre fora um homenzinho egoísta, um amante preguiçoso e um marido ensimesmado" (p. 56). Seu andar por Lisboa é de contemplação e despedida:

Contemplo. Assim se vão as águas desse rio, penso, olhando o formoso Tejo meu, a ponte, os barcos iluminados, fundeados a meio das turvas águas do seu curso, as casas e os morros que despontam do outro lado do estuário, e de todos estes povos ou povoados vizinhos de Lisboa, num cenário que já foi onírico e grandioso, e agora se me afigura estático e imutável. De museu. Parece impossivel que este mesmo rio tenha sido cantado por Camões, Bocage, Fernando Pessoa, tantos outros poetas [...] Contemplo. As luzes, as docas, os comboios iluminados, as casas altas da Ajuda do Bairro Alto de Alfama, da Mouraria e o mais que não sei se contemplo, se desejo, se apenas adivinho no meu conhecimento geográfico de Lisboa. (p. 29)

Com a morte do pai, sente perder a raiz maior que o ligava a terra. Decide lecionar em Poitiers, ir embora. "Despeço-me das casas, das vozes, da sabedoria e da paisagem portuguesa” (p. 216). Repassar a geografia urbana de Lisboa era o ritual necessário de reafirmação da identidade ameaçada agora por uma Europa que chegava, inventando uma viagem inversa a dos portugueses navegadores. Não era mais 
Portugal que saia, mas a Europa que invadia o seu território, não mais com os povos bárbaros vindos do leste, mas com algo mais assustador: a estranha cultura civilizatória a ameaçar a memória afetiva dos mitos construtores da identidade nacional:

Tenho agora Portugal inteiro na minha frente. Começaram a nascer os filhos da Europa. E estão morrendo os velhos portugueses - tanto os crentes como os incrédulos. Se aos filhos não pudermos falar da vida e da nossa terra, que coisas iremos nós ensinar aos filhos da Europa, que não seja uma teoria, ou a arte e a manha, ou artimanha de todos nos considerarmos fingidamente europeus? (p. 165)

$\mathrm{O}$ andar por Lisboa para essa personagem também era olhar para um espelho, rever a própria história impressa na memória cotidiana da cidade; acomodar a visão sobre si mesma e sobre a passagem do tempo. Não nascera lá. Viera de ilhas igualmente míticas, dissera adeus à mitologia do céu e do mar. "Não vim só para viver em Lisboa, mas para de mim me perder por Lisboa” (p. 14). Caminhar pela cidade é olhar para ela buscando a certeza do que ainda não se perdeu, mesmo sob esse "firmamento subitamente neo-europeu” (p. 17). Ainda é a mesma cidade, mantida a sua paisagem, as casas, os monumentos, o vai-e-vem das avenidas e o sobe e desce dos barcos no cais:

E há as casas. As casas, as casas. Sim as casas de Lisboa possuem uma espécie de concretude partida ao meio, entre o real e o

14 ALMEIDA, Onésimo Teotônio. Pessoa, Portugal e o futuro. Lisboa: Gradiva, 2014.

15 António Quadros, “Fernando Pessoa recriador de mitos" Apud, ALMEIDA, Onésimo Teotônio. Pessoa, Portugal e o futuro. Lisboa: Gradiva, 2014. onírico. Metade da sua realidade consiste naquilo que nos é quotidiano, feito da nossa razão e à nossa medida: a idade, as coisas que nos afrontam ou nos dão prazer - os trabalhos e os dias, a estranheza e a familiaridade de tudo o que se pode tanger, tocar, possuir. A outra metade tem a dimensão do sonho: por exemplo, esta ideia de ver Lisboa em arco, na diagonal do meu ângulo de visão, e imaginar uma cidade em repouso e em suspensão, dentro e fora de si mesma. Exatamente como nos sonhos. (p.12)

O vagar pela cidade acaba por repetir uma viagem. Mas não ao passado. Há um olhar de futuro em tudo o que é visto. Todos os mitos fundacionais revistos como expressão de um povo que foi formado por muitos que ali chegaram e foram barrados pelo mar. O mesmo mar que foi também caminho de saída.

Revendo o conceito de mito em Fernando Pessoa, Onésimo Teotônio Almeida em sua obra Pessoa, Portugal e o futuro ${ }^{14}$, afirma que, "em vez de fixado no passado, o mito é todo projetado no futuro":

...existindo como agente no processo da sua consecução, apontando o caminho para a verdade que vai sendo construída, ou servindo para apontar esse caminho mesmo que ele esteja ainda envolto em nevoeiro. (p.176.)

Segundo António Quadros ${ }^{15}$, há uma potência regeneradora no mito. $E$ isso se torna mais claro em Mensagem de Fernando Pessoa. Há um roteiro na obra a guiar o seu leitor pelos mitos dos criadores da nação portuguesa. Assim como na obra A cidade de Ulisses, em $O$ cerco de Lisboa e em $O$ homem suspenso, em Mensagem há uma caminhada pelas camadas da história e pelos mitos que as fizeram. Não reconhecemos 
imediatamente a nação representada ali pelos títulos dos poemas. Há uma dualidade expressa de caráter nacionalista e ao mesmo tempo místico em cada um. Exibe uma predestinação geográfica, "o rosto com que fita, Portugal” - e uma predestinação histórica ${ }^{16}$ com "Viriato" e o “Conde D. Henrique”, por exemplo:

Frequentemente acusado de mistificação, fingimento, insinceridade num domínio onde, ainda hoje, muito boa gente exige autenticidade e confessionalismo - refiro-me ao domínio da poesia - Fernando Pessoa constitui um dos casos mais enigmáticos da Literatura Portuguesa. ${ }^{17}$

José Martins Garcia referia-se a heteronímia do poeta. Porém em Mensagem, Pessoa escreveu como ele mesmo. Ainda assim, passando o protagonismo de cada poema aos seus mitos. Dá voz aos pais da nação, nobres e plebeus, sendo D. Sebastião o grande homenageado. Porém, no último poema da segunda parte, permite-se colocar na voz do sujeito lírico, a própria voz numa prece dirigida ao Encoberto:

Screvo meu livro à beira-mágoa

Meu coração não tem que ter.

Tenho meus olhos quentes de água.

Só tu, Senhor, me dás viver.

Quando virás, ó Encoberto,

Sonho das eras português,

Tornar-me mais que o sopro incerto

De um grande anseio que Deus fez?(p.85)

Em A Cidade de Ulisses, há um momento em que Paulo se deixa levar pelas recordações de quando vivia com Cecília, quando também rememora Pessoa, como alma impregnada da cidade:

\begin{abstract}
A sua chávena de café, o cigarro, o cálice de aguardente, a monotonia dos dias, as ruas melancólicas da Baixa, a autopiedade do menino da sua mãe, a saudade do tempo em que festejavam o dia dos seus anos e ninguém que ele amasse estava morto. $O$ spleen, $a$ neurose, a melancolia. Ser ou não ser, numa versão mansa, à beira desse rio. Pessoa foi pouco ou nada em vida, o seu baú de sonhos ajuda-nos a encher o vazio, ou a essência dos nossos. Estamos viciados como ele na embriaguez do que não foi, não tomou forma, não passou do esboço, de coisa inacabada, mas poderia ter sido todas as coisas do mundo. Pessoa é um baú inesgotável porque a nossa melancolia nos faz cair lá dentro e não achar saída. A poesia mortal, o gume da faca que revolvemos na carne. A ferida que não sara. A palavra. (p.38)
\end{abstract}

Em uma obra dedicada a Lisboa como a cidade fundada por um mito, não poderia deixar de aparecer em algum momento a figura do poeta que mais representa a alma da cidade, $o$ mistério oculto da multiplicação do gênio, o homem que caminhava pela cidade como pelos corredores da sua casa, que escrevia nos seus cafés, e amava o seu rio; o pastor amoroso, “O Tejo é mais belo que o rio que corre pela minha aldeia"18; o engenheiro futurista de Lisbon Revisited - "Ó macio Tejo ancestral e mudo, Pequena verdade onde o céu se reflete! Ó mágoa revisitada, Lisboa de outrora de hoje!" ${ }^{19} \mathrm{O}$ médico que conversava com os deuses - "Cada

16 PESSOA, Fernando. (Org. Cleonice Bernardinelli) Mensagem. Rio de janeiro: Edições de janeiro, 2014. 17 GARCIA, José Martins. Exercício da crítica. Lisboa: 1995, p.60.

18 Alberto Caeiro in Pessoa, Fernando. Obra poética de Fernando Pessoa. Rio de Janeiro: 2016, p.42.

19 Idem, Álvaro de Campos, p.236. 
coisa a seu tempo tem seu tempo. Não florescem no inverno os arvoredos, Nem pela primavera Têm branco frio os campos”. ${ }^{20}$

A exposição aconteceu. De acordo com o olhar de Cecília, a cidade de Ulisses foi apresentada. "Este, que aqui aportou, Foi por não ser existindo. Sem existir nos bastou”. Cecília havia deixado por escrito, para o caso de acontecer-lhe algo, que todos os seus trabalhos inacabados fossem entregues a Paulo. Ele organizou tudo como ela havia idealizado: "Gravavas imagens de uma Lisboa imaginada e cobri-las de palavras, como um corpo com que se faz amor”.21

Lá na Poética aprendemos que não é ofício do poeta narrar o que aconteceu, mas representar o que poderia, o que seria possível segundo a verossimilhança e a necessidade. "Fingir a dor que deveras sente”. Aristóteles nos deixou a ideia de que a poesia trabalha ações humanas provindas do mito e explica que o Mythos se constitui de ações (prattein), plural de práxis; caracteres (ethos), comportamento, ética; e pensamento (dianoya) razão ou racionalidade. $\mathrm{O}$ sábio grego diz também que o Mito é sempre uma história sagrada, que não pode ser verificada nem submetida à prova da verdade, porque está guardada num tempo remoto. $\mathrm{O}$ Mito é fábula e ação.

Voltando a Magritte: existe prazer na contemplação dessas imagens porque não são aquilo que representam; são a representação daquilo apenas. Teolinda Gersão, Saramago, João de Melo, Fernando Pessoa e tantos outros

20 Idem, Ricardo Reis, p.103.

21 GERSÃO, Teolinda. A cidade de Ulisses. Rio de Janeiro: Oficina Raquel, 2017, p.236. autores portugueses nos levam a caminhar por histórias fictícias cheias de verdades históricas, de camadas de memórias afetivas e de mitos fantásticos. A literatura portuguesa desde sempre discute o fato de que não foi a história que determinou os mitos, mas os mitos determinaram os rumos da história. São os mitos que conduzem aos fatos e não o contrário. Não importa o exato lugar da cerca moura, ou se Ulisses, o herói grego, deixou marcas além do seu nome na cidade de Lisboa. Importa a verdade e a força de todas as narrativas que contaram essa história.

\section{REFERÊNCIAS BIBLIOGRÁFICAS}

ALMEIDA, Onésimo Teotônio. Pessoa, Portugal e o futuro. Lisboa: Gradiva, 2014.

ARMSTRONG, Karen. Breve história do mito. São Paulo: Companhia das Letras, 2005.

ARISTÓTELES. Poética. São Paulo: Ars Poética, 1992.

CAMÕES, Luis Vaz de. Os Lusíadas. Rio de Janeiro: Biblioteca do Exército, 1980.

COSTA, Lígia Militz da. Mimese e verossimilhança: na Poética de Aristóteles e na teoria da literatura contemporânea. Porto Alegre: 1986. 303p. Tese de doutorado em Letras (Teoria da Literatura), Pontifícia Universidade Católica do Rio Grande do Sul.

GARCIA, José Martins. Exercício da crítica. Lisboa: 1995.

GERSÃO, Teolinda. A cidade de Ulisses. Rio de Janeiro: Oficina Raquel, 2017.

HOMERO. (Tradução Trajano Vieira) Odisseia. São Paulo: Editora 34, 2013. 
HOMERO. (Tradução Donald Schüler) Odisseia. Porto Alegre: L\&PM, 2014.

JAEGER, Werner. Paideia - A formação do homem grego. São Paulo: [s.d.]

MAY, Rollo. À procura do mito. São Paulo: Manole, 1992.

MELO, João de. O homem suspenso. Lisboa: Publicações D. Quixote, 1996.

PAGE, Martin. A primeira aldeia global - como Portugal mudou o mundo. Alfragide: Casa das Letras, 2012.
PESSOA, Fernando. Mensagem. São Paulo: Companhia das Letras, 1998.

PESSOA, Fernando. (Org. Cleonice Bernardinelli) Mensagem. Rio de Janeiro: Edições de Janeiro, 2014.

PESSOA, Fernando. Obra poética de Fernando Pessoa. Rio de Janeiro: 2016.

QUADROS, António, "Fernando Pessoa recriador de mitos” Apud, ALMEIDA, Onésimo Teotônio. Pessoa, Portugal e o futuro. Lisboa: Gradiva, 2014. SARAMAGO, José. História do cerco de Lisboa. São Paulo: Companhia das Letras, 2011. 